\title{
Fluctuations in Blood Glucose level of Donkeys Infected with
}

\section{Trypanosoma evansi}

\author{
Garba U.M ${ }^{1 *}$, Mayaki A.M ${ }^{2}$ \\ ${ }^{1}$ Veterinary Clinic, Equitation Dept, Nigerian Defence Academy, P.M.B. 2109, Kaduna, Nigeria \\ ${ }^{2}$ Department of Veterinary Medicine, Faculty of Veterinary Medicine, Usmanu Danfodiyo University Sokoto, \\ Nigeria
}

*Corresponding Author: Garba U.M, Veterinary Clinic, Equitation Dept, Nigerian Defence Academy, P.M.B. 2109, Kaduna, Nigeria. Email: garbaum@yahoo.com

\begin{abstract}
The aim of this study was to determine fluctuations in blood glucose level of donkeys experimentally infected with Trypanosoma evansi. Apparently healthy donkeys were assigned to experimental groups $A_{1}, A_{2}$ and $B$ of 6 animals each. The animals were housed in prepared pen and zero-grazed. Groups $A_{1}$ and $A_{2}$ were infected with about $2.0 \times 10^{6}$ T. evansilanimal through jugular vein. Group $A_{2}$ animals were treated with isometamidium chloride (1\%), $0.5 \mathrm{mg} / \mathrm{kg}$ body weight, deep I.M. once. Group B was uninfected control. Parasitaemia and blood glucose levels were evaluated using Light Microscopy and digital Blood Glucose Monitor respectively in the phases of experiment. System Analytical Statistics corporation-2010 was used to analyse data. Means of parasitaemia and blood glucose levels have been presented graphically. Analysis of Variance was used to compare group means of variables at 95\% confidence level. Results showed undulating parasitaemia wave in early stage of infection and became latent in infected-untreated group in chronic stage. Treatment with isometamidium caused mean parasitaemia to drop to 0/field but Mice inoculation tests for the group, revealed relapse in 3/5(60\%) in chronic stage. Mean blood glucose level of group $A_{1}$ increased significantly $(P<0.05)$ from pre-infection value of $72.7 \pm 1.0 \mathrm{mg} / \mathrm{dL}$ to $77.7 \pm 0.1 \mathrm{mg} / \mathrm{dL}$ on day 7 post-infection. Blood glucose level declined from day 14 significantly $(P<0.05)$ decreased to $35.8 \pm 0.6$ $\mathrm{mg} / \mathrm{dL}$. Group $A_{2}$ pre-inf. glucose level $(59.0 \pm 0.7 \mathrm{mg} / \mathrm{dL})$ increased significantly $(P<0.05)$ to $78.0 \pm 0.8 \mathrm{mg} / \mathrm{dL}$ between dayl4 and 21 post-treatment $(P T)$ but decreased significantly $(P<0.05)$ on day 28 PT to $66.2 \pm 2.6 \mathrm{mg} / \mathrm{dL}$ becoming constant till end of experiment on day $119 \mathrm{PT}$. It was concluded that blood glucose level of donkeys with surra but untreated, fluctuates with initial transient hyperglycaemia and later persistent hypoglycaemia which extends to chronic stage of infection. Treatment of donkeys with standard dose of isometamidium is associated with slight but persistent hyperglycemia PT.
\end{abstract}

Keywords: Blood Glucose, Donkeys, Fluctuations, Trypanosoma evansi.

\section{INTRODUCTION}

Trypanosoma evansi (T. evansi) infection (surra) is widespread in the tropical and subtropical areas of the world such as Asia, Africa, Middle East, Central and South America causing great economic loss due to reduced traction power [1] and death of affected animals [2]. Camels, cattle horses, donkeys, zebra, mules, dogs and pigs are amongst the animals affected and lose weight progressively until they ultimately die [3,4]. The transmission of $T$. evansi among animals is mechanical, by biting flies especially by those of the genera; Tabanus $s p$, and Stomoxys sp, Haematopota $s p$, Lyperosia sp and Chrysops sp [5] as well as transplacentally in donkeys [6].

In Nigeria, donkeys are widespread and owned by both pastoralists and farmers especially in the Northern part who use them as source of

ARC Journal of Animal and Veterinary Sciences traction power or means of transport [7] because they are easy to manage as they tolerate some tropical diseases and parasites, survive on poor quality feeds and thrive under adverse climatic conditions [8] unfortunately scientific data available on donkeys is scanty due to little research attention accorded the animal specie [7].

Despite the benefits and advantages of keeping donkeys, surra remains a protracted and fatal disease of camels and equids in Nigeria [9], that is limiting the work efficiency and productivity of affected animals [1] and other variable pathologies such as hypoglycemia in camel [10] and rat [11]. In this study, blood glucose levels of donkeys was evaluated pre-infection, postinfection and post-treatment with isometamidium chloride with a view to understanding the fluctuations in blood glucose 
levels of donkeys with Trypanosoma evansi infection (surra) and provide additional scientific data for understanding of surra disease in donkeys.

\section{Materials ANd MeTHOdS}

\subsection{Experimental Animals}

Eighteen apparently healthy donkeys were purchased from Livestock Market in Maigatari town and used for this experiment. The donkeys were 11 to 15 months old as estimated using eruption pattern of the incisors teeth $[12,13]$ and body condition scores were between 4-6 (medium) using the 9 points scale system [14].

Four (4) apparently healthy and haemoparasitesfree, adult albino Wistar rats, with body weight range of 200g-220g were used as donors for the propagation of $T$. evansi to obtain sufficient inoculum for the experimental infection.

\subsection{Management and Pre-infection Evaluation of Experimental Animals \\ 2.2.1.Housing and Feeding of Experimental Animals}

The donkeys were housed according to grouping in the experimental animal pen of the Department of Veterinary Parasitology and Entomology, Ahmadu Bello University, Zaria. Animals were further examined for signs of disease and external parasites infestations. Wood shaving was used as bedding material in the pen, mucked daily to remove faecal droppings and changed as soon as the old one was bad. Experimental animals were acclimatized for 14 days [15].

The donkeys were provided with feed daily equivalent to $5 \%$ of their mean body weight, in the forms of Sorghum/Maize stovers and Rhodes grass/groundnuts hay (4:1 ratio), and the concentrate feed consisted of a mixture of sorghum grain $(500 \mathrm{~g})$, dried groundnut cake $(130 \mathrm{~g})$ and Maize/Wheat bran $(2.5 \mathrm{~kg})$ per 200 $300 \mathrm{~kg}$ bd wt of animal. Salt lick blocks, rich in dicalcium phosphate and clean drinking water were provided ad-libitum as recommended by Aganga et al [8].

The albino rats and Wister mice were maintained in separate, labeled cages and were provided with commercially obtained pelletised feed in feeders and clean drinking water in sipper tubes ad libitum [15].

\subsubsection{Screening for Parasites}

About $5 \mathrm{~g}$ faecal sample was collected from the rectum of each animal and examined for gastrointestinal parasites using floatation and sedimentation methods [16] to ascertain parasites load. The animals were dewormed using fenbendazole bolus (Fenacure ${ }^{\circledR}$, Ashish Life Sciences PVT Itd, India) at the dose rate of $10 \mathrm{mg} / \mathrm{kg}$ bd wt orally, once [17].

Four milliliters $(4 \mathrm{~mL})$ of whole blood was collected from jugular vein of each animal using $5 \mathrm{~mL}$ syringe and $18 \mathrm{G}$ needle. Three milliliters $(3 \mathrm{~mL})$ of the blood was stored in sterile tubes containing liquid tripotassium salt of Ethylene Diamine Tetra-acetate (EDTA $\mathrm{K}_{3}$ ), $1 \mathrm{mg} / \mathrm{mL}$ of whole blood as anticoagulant [18] and examined immediately for haemoparasites infections using 2 preparations each of Wet Blood Film (40x objective), micro haematocrit centrifuge tube and Giemsa Stained thin blood smear (100x oil immersion objective) [19]. An average of 20 microscope fields was examined from each preparation.

Animal inoculation: The balance of $1 \mathrm{~mL}$ of blood collected from each donkey was transferred into sodium heparin-coated $1 \mathrm{~mL}$ sterile disposable syringe with $25 \mathrm{G} \times 1 \frac{1}{2}$ inch needle and $0.5 \mathrm{~mL}$ of the blood was injected into a mouse intra-peritoneally [15] using 2 representative mice per donkey [20]. The inoculated mice were monitored for haemoparasites by examining their tail tip blood using Haematocrit Centrifugation Technique and Wet Film at 48 hours intervals for 14 days [21], and remained under observation up to 60 days post-inoculation.

\subsubsection{Identification and Grouping of Animals}

Serially numbered aluminum plate (about $5 \mathrm{~g}$ ) neck-tags were assigned to the donkeys for identification. A sample frame of each gender was prepared and treated one after the other by random picking of animals and placing in experimental groups $A_{1}, A_{2}$ and $B$ to obtain a total of 6 animals ( 3 male and 3 female) in each experimental group. Choice of groups of animals inoculated with $T$. evansi as well as assigning of Isometamidium chloride treatment was made randomly [22].

The rats and mice were caged according to the group of donkeys they represented. Marks were applied on the various body parts of the rats and mice using permanent marker to reflect the donkey they represented.

\subsection{Evaluation of Blood Glucose levels}

The ear vein of each restrained experimental animal in all groups was swabbed and pricked using sterile $18 \mathrm{G}$ needle to obtain a drop of 
whole blood as reported by Weiser [23] and Wolfensohn and Lloyd [15]. The drop of whole blood (about $0.7 \mu \mathrm{L}$ ) was placed on the test strip of a digital blood glucose monitor (Fora ${ }^{\circledR} \mathrm{G} 20$, Fora Care Inc., U.S.A.) to assay blood glucose level as recommended by the manufacturer. The level of glucose in blood was displayed on the digital monitor screen in $\mathrm{mg} / \mathrm{dL}$. The tests were conducted within the pen between 06.00 a.m. and 08.00 a.m. local time to minimize the influence of feeding [24]. Samples were collected at 7 days interval (weekly) during the pre-infection (baseline data) $\mathrm{x} 4$, post-infection (x4) and post-treatment (x20) phases of experiment.

\subsection{Propagation of Trypanosoma evansi}

Trypanosoma evansi originally isolated from camel and maintained in Wistar rats was obtained from the Department of Veterinary Parasitology and Entomology, Ahmadu Bello University, Zaria and used in this experiment. The level of parasitemia of the infected Wistar rat was first determined to be +4 (representing greater than 20 parasites per field of microscope after examining 20 fields) on haematocrit centrifugation technique (HCT). One milliliter of parasitaemic blood was collected via ocular vein into heparinised sample bottle and diluted with $1 \mathrm{~mL}$ phosphate buffered saline glucose solution. About $0.5 \mathrm{~mL}$ of the inoculum was inoculated into each of a set of 4 donor rats, intra-peritoneally using sterile $1 \mathrm{~mL}$ disposable syringe, $25 \mathrm{G}_{\mathrm{X}} 1 \frac{1}{2}$ inch needle $[21,15]$.

The donor rats were monitored for parasitaemia levels at 48 hours intervals using Wet Film method [20] for 12 days post-inoculation at the end of which the 4 rats showed between +2 to +4 (6-10 to $>20$ parasites per microscope field) parasitaemia levels. The 4 donor rats were bled and the blood was pooled into a sterile conical flask containing heparin sodium 20 Units $/ \mathrm{mL}$ of blood. A total of $15 \mathrm{~mL}$ parasitaemic-pooled blood was obtained and the parasitemia was reevaluated using haemocytometer [18]. The parasitaemic-blood was diluted with phosphate buffered saline glucose solution giving $1.0 \times 10^{6}$ T. evansi $/ \mathrm{mL}$ of inoculum [21].

\subsection{Experimental Infection and Monitoring of Parasitaemia}

The experimental animals in groups $\mathrm{A}_{1}$ and $\mathrm{A}_{2}$ were immediately infected with prepared inoculum using $2 \mathrm{~mL}\left(2.0 \times 10^{6}\right.$ T. evansi $)$ per animal through the jugular vein. Infection day was considered as day0 of infection. Group B animals remained as Un-infected (control). Parasitaemia levels were evaluated postinfection (PI) daily from day 0 to 7 and twice per week ( 3 and 4 days apart) from day 7 to 28 using ear vein blood examined on HCT and Giemsa-stained thin blood smears [20,25]. Levels of parasitemia were scored using Woo method [26].

\subsection{Treatment of Infected Animals and Monitoring of Parasitaemia}

Following the observation of a third wave of parasitaemia in all infected animals on day 28 PI, group $\mathrm{A}_{2}$ animals were treated using isometamidium chloride (Securidium $^{\circledR}$, Laprovet, France) $1 \%$ solution at the dose rate of $0.5 \mathrm{mg} / \mathrm{kg}$ bd wt by deep intramuscular injection once [17]. The treatment day was considered as day0 of treatment.

Parasitaemia levels were monitored posttreatment (PT) daily from day 0 to 7 , twice pe week ( 3 and 4 days apart) from day 7 to 28 and at seven days intervals from day 28 to 147 to determine the effects of isometamidium chloride treatment in controlling infection and consequently possible restoration of glucose levels to pre-infection values in treated animals.

\section{Data ANALYSIS}

System Analytical Statistics (SAS) corporation2010 was used to compute means of values of variables for groups of animals and graphs were prepared using Microsoft Excel 2010. Analysis of Variance (ANOVA) was used to compare means of variables between experimental animal groups and within groups at $95 \%$ confidence level, where $\mathrm{P}<0.05$ was considered statistically significant [27].

\subsection{Ethical Considerations}

The welfare of the experimental donkeys was according to the guidelines on accommodation and care for animals used for experiment and other scientific purposes of the European Communities, contained in Appendix-A of Council Directive 86(609)EEC, 'Directive 2010/63' and approved by the Ahmadu Bello University Research and Ethics Committee in Zaria, Nigeria.

\section{RESUlT}

\subsection{Parasitaemia Levels in Groups of Donkeys Infected with Trypanosoma evansi}

\subsubsection{Post-Infection Parasitaemia}

Some of the animals in the T. evansi-infected groups $\left(A_{1}\right.$ and $\left.A_{2}\right)$ were became positive for the 
parasite on day 3 and by day 4 , all animals in the 2 groups were positive. Parsitaemia levels increased gradually from day 3 with undulating waves that peaked on days 7 , and 18. A third rising-wave of parasitaemia was observed on day 28 in the two infected groups and animals in group $\mathrm{A}_{2}$ were treated (arrowed on $\mathrm{X}$-axis of Fig.1).

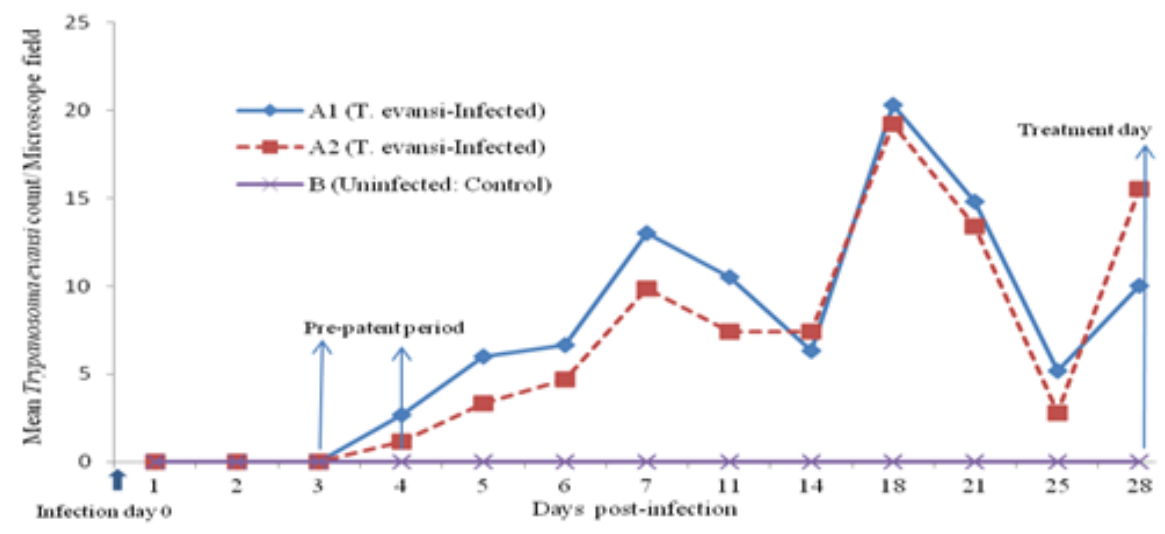

Fig1. Mean levels of parasitaemia in donkey experimentally infected with Trvpanosoma evansi

\subsubsection{Post-Treatment Parasitaemia}

\section{Group $A_{1}$ (Infected-Untreated)}

Direct examination of the blood of infecteduntreated group of donkeys using HCT showed an undulating wave of parasitaemia at the beginning but became aparasitaemic on day 100 PI (equivalent to day 72 PT) (Fig.2). However, mice inoculation test (MIT) on day 110 PI resulted in death of all inoculated mice by day 15 post-inoculation from heavy parasitemia observed to be +3 to $+4 /$ field on HCT. This indicated that there was latent infection in Infected-untreated animal group as at day 100 PI.

\section{Group $A_{2}$ (Infected, Isometamidium Chloride-} Treated)
The T. evansi-infected, isometamidium chloride-treated group of animals showed sudden drop in mean parasite count from approximately 12/field on day 1 to about $2 /$ field on day 2 PT but by day $11 \mathrm{PT}$, the group was aparasitaemic on HCT (Fig.2). Mice inoculation tests (MIT) on this group on days 21 and 50 were negative for all animals but by day 100 PT, $6 / 10(60 \%)$ of mice were positive (showing only 1 parasite, $1+$ per microscope field) representing $3 / 5(60 \%)$ of donkeys in the group while negative mice accounted for 4/10(40\%) representing 2/5 (40\%) of donkeys. Mice were monitored for 48 days post-inoculation during which the positive $(60 \%)$ and negative $(40 \%)$ mice maintained their 1 parasite (1+) per microscope field and negative status respectively.

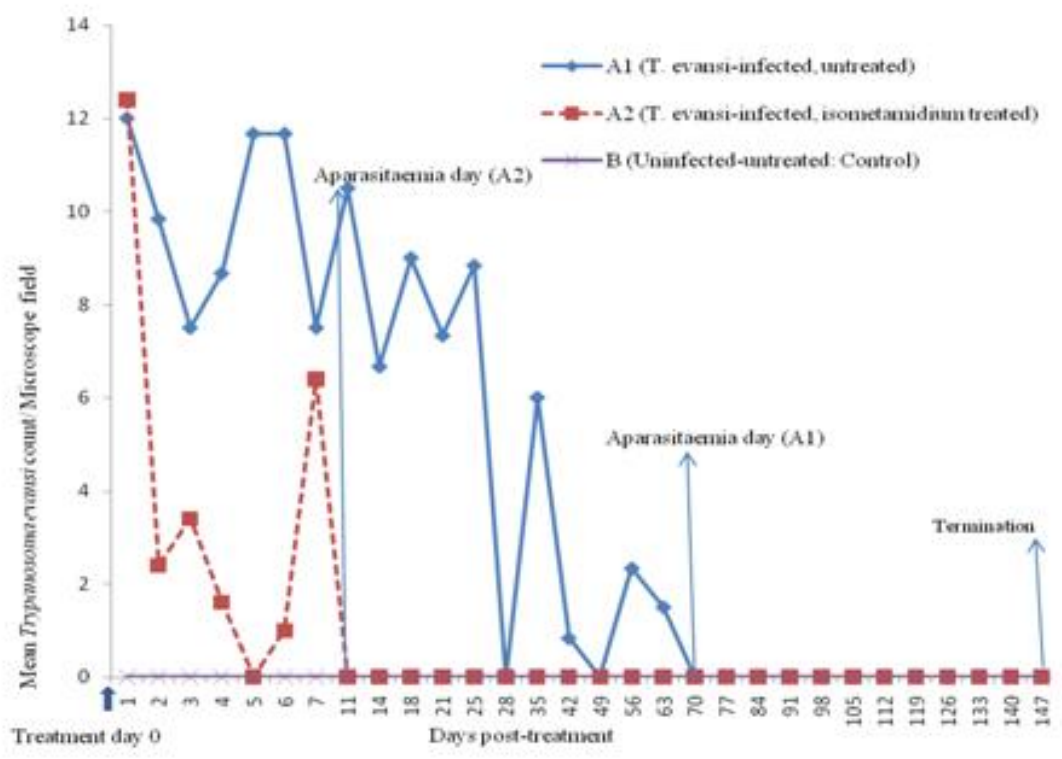

Fig2. Mean Levels of Trvpanosoma Evansi Observed in Experimentally Infected Donkeys Post-Treatment 
Group B (Un-Infected,Un-Treated)

Animals in this group remained negative throughout the experiment.

\subsubsection{Fluctuations in Mean Blood Glucose Level}

\section{Group $A_{1}$ (T. Evansi-Infected-Untreated)}

The mean pre-infection (Pre-I) value was $72.7 \pm 1.0 \mathrm{mg} / \mathrm{dL}$. The mean glucose value increased significantly $(\mathrm{P}<0.05)$ on day 7 post- infection (PI) to $77.7 \pm 0.1 \mathrm{mg} / \mathrm{dL}$. Fourteen (14) days PI, the blood glucose level began to declined and by day 42 PI (equivalent to day 14 $\mathrm{PT})$ it had significantly $(\mathrm{P}<0.05)$ decreased to $35.8 \pm 0.6 \mathrm{mg} / \mathrm{dL}$. There was gradual rise to $62.0 \pm 2.5 \mathrm{mg} / \mathrm{dL}$ on day $105 \mathrm{PI}$ (equivalent to day 77 PT) elevating the value to near pre-incfection value and remained constant to the end of experiment on day 147 PI (equivalent to day 119 PT) (Fig.3).

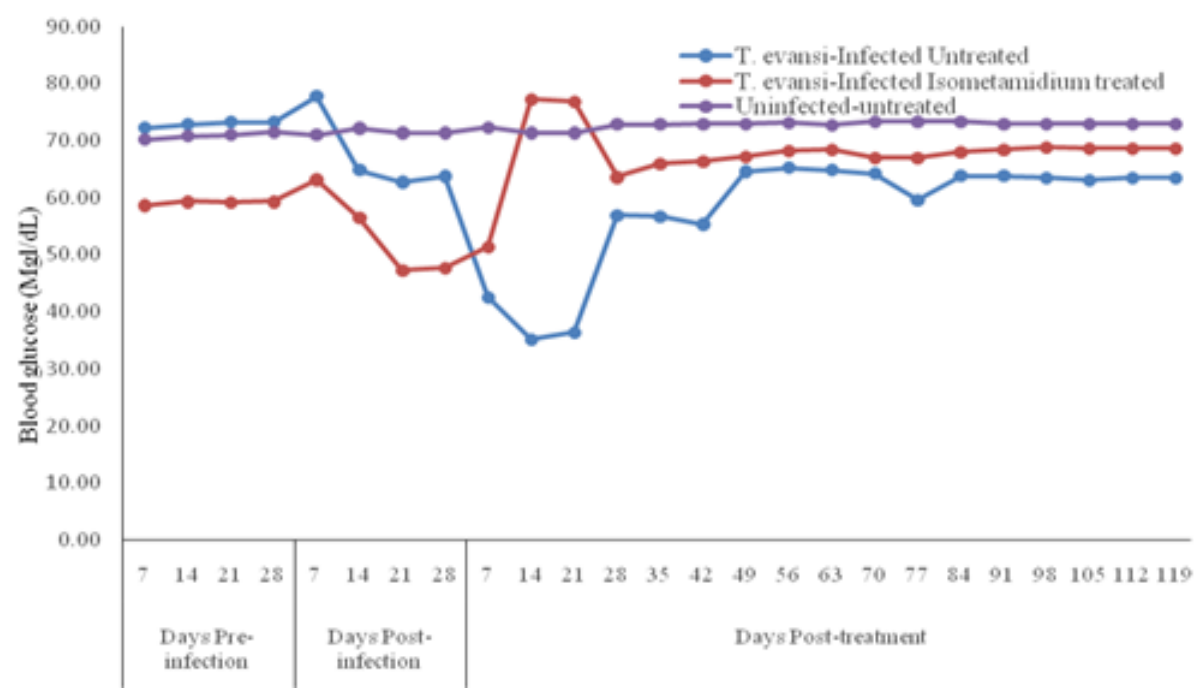

Fig3. Trend of Fluctuations in Mean Blood Glucose Levels of Donkeys Experimentally Infected with Trvpanosoma evansi in the Three Phases of Experiment

Group $A_{2}$ (T. Evansi-Infected, IsometamidiumTreated)

The mean pre-infection value was $59.0 \pm 0.7 \mathrm{mg} / \mathrm{dL}$. On day $14 \mathrm{PI}$ animals began to show decline in blood glucose levels which significantly $\quad(\mathrm{P}<0.05) \quad$ decreased to $47.5 \pm 0.2 \mathrm{mg} / \mathrm{dL}$ between day 21 and $28 \mathrm{PI}$. Following treatment with isometamidium chloride, there was significant $(\mathrm{P}<0.05)$ rise in glucose level $(78.0 \pm 0.8 \mathrm{mg} / \mathrm{dL})$ between day 14 and 21 PT. From day 28 PT blood glucose reversed to $66.2 \pm 2.6 \mathrm{mg} / \mathrm{dL}$ which was significantly $(\mathrm{P}<0.05)$ above pre-infection value and was maintained at the level to the end of experiment on day 119 PT (Fig.3).

\section{Group B (Uninfected-Untreated)}

The control group maintained blood glucose level of $71.8 \pm 1.6 \mathrm{mg} / \mathrm{dL}$ throughout the experiment (Fig.3).

\section{DISCUSSION}

In this study, there was sudden rise in blood glucose levels of all T. evansi-infected groups of animals in early stage of infection which coincided with the period of high parasitemia in the groups of $T$. evansi-infected animals. The observed rise suggest host-organ damage at cellular level due to toxic releases from parasites and immune complexes [28, 29]. Acute injury to pancreas might have reduced insulin activity to control blood glucose level [30] resulting in the sudden rise in glucose level observed in early stage of infection. As T. evansi infection persisted, the blood sugar levels of donkeys declined. This finding can be explained by the reports that host glucose reserve is increasingly utilized and depleted by host animal body cells in febrile condition [31], blood stream form trypanosome, trypomastigote [32] and in presence of hepatocytes degeneration [33] in trypanosomosis due to increased demand for metabolism resulting in hypoglycemia [10]. These factors contribute to depletion of glucose in Trypanosoma evansi infected donkeys $[34,35]$. There was improvement in blood glucose level observed in the chronic stage of infection in this study. This may be due to decrease in parasitaemia level in chronic stage [36] due to curtailment by host immune system [31] and consequently reduced glucose demand by parasites at later stage of the disease [32]. However, the persistence of hypoglycemia in 
infected-untreated groups of donkeys reflects lack of parasite control or cure in the groups [36].

Animals treated with isometamidium chloride showed immediate improvement in mean blood glucose level, which agreed with similar report on rat model [11]. However, the observe high rise of glucose post-treatment above preinfection level and its later sustenance slightly above the pre-infection level, suggests functional damage to pancreatic islet cells as organ damage at cellular level have been reported as a major finding in $T$. evasi infection (surra) in donkeys [35, 37]. Similarly, treatment with isometamidium chloride which belongs to the same chemical group as homidium [38] is reported to be toxic to other species of animals [17].

\section{CONClusion}

It was concluded that blood glucose level of donkeys with surra fluctuates with initial transient hyperglycaemia and later persistent hypoglycaemia that extends to chronic stage of $T$. evansi infection. Donkeys treated with standard dose of isometamidium show slight but persistent hyperglycemia.

\section{RECOMMENDATIONS}

Donkeys diagnose as positive for surra, should be evaluated for blood glucose level to enable decision making on the need or otherwise for improved high energy feed (bran and grains) and or glucose-rich fluid therapy and allow animal under treatment to rest from work. Further study should be conducted on insulin activity especially during the periods of transient hyperglycaemia and in animals treated with isometamidium to obtain further histochemical explanations for the fluctuations.

\section{ACKNOWLEDGEMENTS}

My appreciations are to: Professor AA Zuru, The Vice Chancellor of Usmanu Danfodiyo University, Sokoto for offering me one year Sabbatical Appointment in the Department of Veterinary Medicine, Faculty of Veterinary Medicine, Usmanu Danfodiyo University, Sokoto and Major Gen MT Ibrahim, Commandant of Nigerian Defence Academy, Kaduna for his approval of my Sabbatical Leave.

\section{REFERENCES}

[1] ILRI (International Livestock Research Institute) Monograph, Disease resistance and protecting the environment, In; Livestock, people and the environment, pp.10-11, (1997).

[2] Da Silva A.S., Zanette R.A., Wolkmer P., Costa M.M., Garcia H.A., Lopes S.T.A., Santurio J.M., Teixteria M.M.G. and Monteiro S.G., Diminazene aceturate in the control of Trypanosoma evansi infection in cats, Vet. Parasitol. 165, 47-50 (2009).

[3] Dia M.L., Diop C., Aminetou M., Jacquiet P. and Thiam A., Some factors affecting the prevalence of Trypanosoma evansi in camels in Mauritania, Vet. Parasitol. 72, 111-120 (1997).

[4] OIE [Office International des Epizootes], Manual of diagnostic tests and vaccines for terrestrial animals [online]. Paris: OIE; Trypanosoma evansi infections (including surra). Retrieved August 27, 2017 from http://www.oie.int/eng/normes/mmanual/2008/ pdf/2.01.17_TRYPANO.pdf (2004).

[5] Luckins, A.G., Trypanosomiasis caused by Trypanosoma evansi in Indonesia, J. Protozool. Res. 144-152 (1999).

[6] Kumar R., Kumar S., Virmani N. and Yadav S.C., Transplacental transmission of Trypanosoma evansi from experimentally infected donkey-mare to neonatal foal, J. Equine Vet. Sci. (2015). DOI: http://dx. doi. org/10.1016/j.jevs.2015.02.004.

[7] Blench R., de Jode A. and Gherzi E., Donkeys in Nigeria: history, distribution and productivity. A resource book of the Animal Traction Network for Eastern and Southern Africa (ATNESA). ACP-EU Technical Centre for Agricultural and Rural Cooperation (CTA), Wageningen, The Netherlands, p. 244 (2013). ISBN 92-9081-219-2.

[8] Aganga A.A., Letso M. and Aganga A.O., Feeding donkeys, Livestock Res. Rural Dev't. 12(2), (2000). http://www.cipav.org.co/lrrd/ lrrd12/2/agan122.htm. Accessed on 12/07/17, 1200 GMT

[9] Ilemobade A. A., Studies on the incidence and pathogenicity of Trypanosoma evansi in Nigeria. 11: The pathogenicity of Trypanosoma evansi for equine and bovine species. ISCTRC, OAU/STRC publication No.105, pp.107-114 (1971).

[10] Stephen L., Trypanosomiasis: A Veterinary Perspective. Pergamon Press, New York, USA, (1986).

[11] Kumar U., Jas R. and Ghosh J.D., Effect of isometamidium hydrochloride on Trypanosoma evansi infections in rats, Parasitic Dis., 33(1-2), 36-41 (2009). DOI: 10.1007/s12639-0090006-3. 
[12] Wayne L. and Melvin B., Determining age of horses by their teeth, Extension and Agricultural Information, 1-98 Agriculture Building, Columbia, MO 65211; XPLOR (2000). website: http://extension.missouri.edu/ publications/index.aspx. Accessed 12:30 GMT July 20, 2017.

[13] Joe A., The Donkey Sanctuary. British Veterinary Association, (2012). Retrieved February 11, 2012 from, www.bva.co.uk.

[14] Pearson R.A. and Ouassat M. A Guide to Livestock Weight Estimation and Body Condition of Donkeys. Centre for Tropical Veterinary Medicine, University of Edinburgh, U.K. and Institut Agronomique et Veterinaire Hassan II, Rabbat, Morocco, 21 pp. (2000).

[15] Wolfensohn S. and Lloyd M., Handbook of Laboratory Animal Management and Welfare. 4th ed. Wiley-Blackwell Publishing ltd, U.K., 371 pp. (2013).

[16] Charles M.H., Internal parasites, External paraspites. In: Charles M.H. and Margi S. (Eds) Laboratory procedures for veterinary technicians. 5th ed. Mosby Elsevier Inc., St Louis Missouri, pp. 187-252 (2007).

[17] Aliu Y.O., Nigerian Veterinary Formulary; Handbook of Essential Veterinary Drugs, Biologics and Pesticide Chemicals. 1st ed., Veterinary Council of Nigeria, p. 67 (2007).

[18] Elaine A. and Margi S. Hematology and hemostasis. In: Charles M.H. and Margi S. (Eds) Laboratory Procedures for Veterinary Technicians. 5th ed. Mosby Elsevier Inc., St Louis Missouri, pp. 27-73 (2007).

[19] Weiser G., Sample collection, processing and analysis of laboratory service options, In: Mary A.T., Glade W., Robin W.A. and Terry W.C. (Eds) Veterinary Hematology and Clinical Chemistry, 2nd ed. Wiley-BlackWell, U.K., pp. 34-50 (2012a).

[20] OIE[Office International des Epizootes], Trypanosoma evansi infection (surra).Version adopted by The World Assembly of Deligates of the OIE in May 2010, Chap 2.1.17. (2010). Retrieved November 24, 2016 from, http:// www.oie.int/fileadmin/Home/eng/Health_stand ards/tahm/2.01.17_TRYPANO.pdf.

[21] Monzon C.M., Mancebo O.A. and Roux J.P., Comparison between 6 parasitological methods for diagnosis of Trypanosoma evansi in the subtropical area of Argentina. Vet. Parasitol. 36, 141-146 (1990).

[22] Aviva P. and Poul W., Statistics for Veterinary and Animal Science. 3rd ed. Wiley-Blackwell ltd, U.K., 391 pp. (2013).

[23] Weiser G., Laboratory technology for veterinary medicine, In: Mary A.T., Glade W., Robin W.A. and Terry W.C. (Eds) Veterinary
Hematology and Clinical Chemistry, 2nd ed. Wiley-BlackWell, U.K., pp. 3-33 (2012b).

[24] De Aluja A.S., Tapia P.G., López F. and Pearson R.A., Live-weight estimation of donkeys in central mexico from measurements of thoracic circumference. Trop. Anim. Hlth Prod., Supplementary, 1, 159-171 (2005).

[25] FAO, Animal production: Section 1, Modul 5, Livestocks Systems Research ManualVolume1. Produced by ILRI, (2014). Retrieved December 16, 2017 from, www.fao.org/ wairdocs/ilri/x5469e/5469e08.htm,

[26] Woo P.T.K., The haematocrit centrifugation technique for the diagnosis of African trypanosomiasis, Acta Trop., 27 (4), 384-386 (1970).

[27] Mead R., Curnow R.N. and Hasted A.M., Statistical Methods in Agriculture and Experimental Biology (Texts in Statistical Science). 3rd ed. Chapman and Hall/CRC, United Kingdom, 488pp (2002).

[28] Enwezor F.N.C. and Sackey A.K.B., Camel Trypanosomosis - A Review, Vet. Arhiv, 75, 439-452 (2005).

[29] Singh B. M., Singla L. D., Kumar H., Vasudev A., Gupta K. and Juyal P. D., Pathological studies on experimental Trypanosoma evansi infection in Swiss albino mice. J. Parasitic Dis., 36(2), 260-264 (2012). Doi:10.1007/s12639-012-0120-5.

[30] Sun Q., Nie S., Wang L., Yang F., Meng Z. and Xiao H., Xiang B., Li X. and Fu X., Factors that affect pancreatic islet cell autophagy in adult rats: Evaluation of a calorie-restricted diet and a high-fat diet, (2016). PLoS ONE 11(3), e0151104.https://doi.org/10.1371/journal. pone. 0151104

[31] Habila N., Inuwa M. H., Aimola I.A., Udeh M.U. and Haruna E., Pathogenic mechanisms of Trypanosoma evansi infection. Res. Vet. Sc., 93 (1), 13-17 (2012).

[32] Fairlamb A.H. and Opperdoes F.R., Carbohydrate metabolism in African trypanosomes with special reference to the glycosome. In: Carbohydrate Metabolism in Cultured Cells (ed. M.J. Morgan), Plenum Publishing, New York. Pp.183-224 (1986).

[33] Von Brand T., Biochemistry of parasites. 2nd ed. Academic, New York, 409pp (1973).

[34] Marques LC., Machado R.Z. and Alessi A.C., Experimental Infection with $T$. evansi in Horses; Clinical and Haematological Observations. Rev. Brasilian Vet. Parasitol., 9, 11-15 (2000).

[35] Cadioli F.A., Marques L.C., Machado R.Z., Alessi A.C., Aquino L.P. C.T. and Baznabe P.A., Experimental T. evansi infection in donkeys: Haematological, biochemical and histopathological changes. Arquivo Brasileiro 
de Medicina Veterinariae Zootecnia (2006). Retrieved July 10, 2016 from http://dx. doi. Org /10.1590/S0102-09352006000500008

[36] Garba U.M., Sackey A.K.B., Lawal A.I. and Esievo K.A.N., Dynamics of parasitaemia in Trypanosoma evansi infection in donkeys and the efficacies of buparvaquone and isometamidium chloride treatments. Anim. Vet. Sc., 4 (3), 32-38 (2016a). Doi:10.11648 /j.avs. 20160403.11 .

[37] Garba U.M., Sackey A.K.B., Lawal A.I. and Esievo K.A.N., Bisalla M. and Sambo J.S.,
Gross and histopathological alterations in experimental Trypanosoma evansi infection in donkeys and the effect of isometamidium chloride treatment. J. Vet. Sc. Anim. Husb., 5 (1), 104 (2016b).

[38] FAO., A field guide for the diagnosis, treatment and prevention of African animal trypanosomiasis, (2012). Retrieved September 22, 2016 from www.///C:/Users/HPUSER/ Documents/ trypanosomes chemotherapy.htm.

Citation: Garba U.M, Mayaki A.M. Fluctuations in Blood Glucose level of Donkeys Infected with Trypanosoma evansi. ARC Journal of Animal and Veterinary Sciences. 2018; 4(1):14-21. doi: dx.doi.org/ 10.20431/2455-2518.0401003.

Copyright: (C) 2018 Authors. This is an open-access article distributed under the terms of the Creative Commons Attribution License, which permits unrestricted use, distribution, and reproduction in any medium, provided the original author and source are credited. 